Case Report

\title{
A Case of Rituximab-Induced Necrotizing Fasciitis and a Review of the Literature
}

\author{
Abdullateef Abdulkareem, ${ }^{1}$ Ryan S. D'Souza, ${ }^{1,2}$ \\ Oluwaseun Shogbesan, ${ }^{1}$ and Anthony Donato ${ }^{1}$ \\ ${ }^{1}$ Department of Medicine, Reading Hospital, West Reading, PA, USA \\ ${ }^{2}$ Department of Anesthesiology, Mayo Clinic Hospital, Rochester, MN, USA \\ Correspondence should be addressed to Abdullateef Abdulkareem; dayo.abdulkareem@readinghealth.org
}

Received 13 July 2017; Accepted 22 August 2017; Published 26 September 2017

Academic Editor: Marie-Christine Kyrtsonis

Copyright (C) 2017 Abdullateef Abdulkareem et al. This is an open access article distributed under the Creative Commons Attribution License, which permits unrestricted use, distribution, and reproduction in any medium, provided the original work is properly cited.

\begin{abstract}
Necrotizing fasciitis is a fulminant soft tissue infection characterized by rapid progression and high mortality. Rituximab is a generally well-tolerated immunosuppresive medication used for B-cell malignancies and some rheumatological disorders. We report a case of a 69-year-old male with chronic lymphocytic leukemia who suffered necrotizing fasciitis of his left lower extremity secondary to Clostridium septicum 7 weeks after treatment with rituximab. Despite immediate intravenous antimicrobial therapy and emergent fasciotomy with extensive debridement, his hospital course was complicated by septic shock and he required an above-the-knee amputation. Physicians need to be aware of the possibility of necrotizing fasciitis in patients presenting with skin infections after rituximab therapy.
\end{abstract}

\section{Introduction}

Necrotizing fasciitis (NF) is a rare, fulminant soft tissue infection characterized by rapidly progressive and extensive destruction of the skin, subcutaneous fat, and fascia [1]. While the incidence of NF is very low ( 0.4 cases per 100,000 adults) [1], it is unfortunately associated with a high mortality rate, ranging between 25 and 73\% [1,2]. Urgent and aggressive surgical debridement is needed, as delayed or inadequate debridement has been linked with increased mortality [24]. Rituximab is an anti-CD20 monoclonal antibody that leads to immunosuppression via depletion of CD20-positive $\mathrm{B}$ lymphocytes, and is indicated for treatment of B-cell hematological malignancies $[5,6]$ and rheumatological conditions including systemic lupus erythematosus (SLE) [7] and rheumatoid arthritis (RA) [8]. We present a case of NF that occurred seven weeks after a course of rituximab infusions in a patient with chronic lymphocytic leukemia (CLL), and review similar relevant cases of rituximab-associated NF.

\section{Case Report}

A 69-year-old male with a history of CLL presented to the emergency department with a 2-day history of progressively worsening left lower limb pain, fever, chills, and malaise. He denied any trauma to his legs, skin breaks, bug bites, nausea, vomiting, weight loss, sick contacts, lymphadenopathy, neurological deficits, or recent travel history. There was no documented history of diabetes, tobacco use, alcoholism, or prior severe infections.

The patient was diagnosed with CD-38 negative CLL eight years prior to admission and was treated 2 years after initial diagnosis with 6 cycles of bendamustine and rituximab after which he was in complete remission. Approximately 11 weeks prior to admission, he was retreated with a 4-week course of rituximab for a resurgence of his CLL, characterized by leukocytosis, anemia, thrombocytopenia, and hypogammaglobulinemia (IgG: $379 \mathrm{mg} / \mathrm{dL}$ (normal: $767-1590 \mathrm{mg} / \mathrm{dL}$ )). This course was completed 7 weeks before admission. 


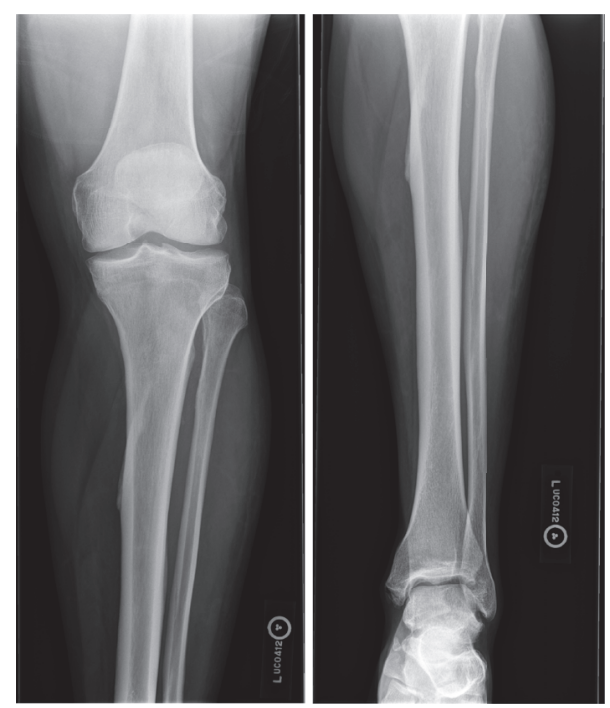

FIgURE 1: Initial X-ray of the left tibia and fibula is displayed. There is mild tibial plafond spurring. No other acute abnormalities are identified.

On initial assessment, he was afebrile $\left(36.5^{\circ} \mathrm{C}\right)$ and other vital signs were normal. Left lower limb examination revealed moderate tenderness to palpation but no erythema or swelling. However, within 7 hours of presentation, the patient was noted to have a fever of $39.2^{\circ} \mathrm{C}$, and pain in his left lower extremity worsened considerably accompanied with extensive tissue induration, new erythema extending from the left ankle to the knees, and subcutaneous emphysema.

Laboratory results were notable for white blood count (WBC) of 5,800 c/ $\mu \mathrm{L}(4,800-10,800 \mathrm{c} / \mu \mathrm{L})$, absolute neutrophil count of $800 \mathrm{c} / \mu \mathrm{L}$, and platelet count of $61,000 \mathrm{c} / \mu \mathrm{L}$ $(130,000-400,000 \mathrm{c} / \mu \mathrm{L})$. Lactic acid was elevated at $3.6 \mathrm{mEq} /$ L $(0.5-2.2 \mathrm{mEq} / \mathrm{L})$. C-reactive protein was elevated at $2.95 \mathrm{mg} / \mathrm{dL} \quad(0.00-0.70 \mathrm{mg} / \mathrm{dL})$. Creatine phosphokinase (CK) level was elevated at $5185 \mathrm{IU} / \mathrm{L}(30-223 \mathrm{IU} / \mathrm{L})$.

Initial X-rays of the lower extremity (Figure 1) and lower extremity arterial duplex studies were normal. CT scan performed three hours after initial X-rays however showed a small amount of gas and subcutaneous fat edema in anterolateral leg, concerning for NF (Figure 2). Two out of four blood cultures grew Clostridium septicum by day 2 .

The patient was started on intravenous broad-spectrum antibiotics including vancomycin and piperacillin-tazobactam. He underwent emergent fasciotomy of the left lower extremity with complete excisional debridement of the anterior compartment and counterincisions of the left dorsal foot and left mediolateral thigh. However, he still required a guillotine left below the knee amputation the following day. Pathological analysis of the excised tissue showed necrotic fibrous tissue consistent with fascia and associated necrotic skeletal muscle.

Postoperatively, the patient was transferred to the intensive care unit due to septic shock requiring norepinephrine infusion to maintain blood pressure; this was successfully weaned by the first postoperative day. During the next three weeks, the patient had a total of seven debridement

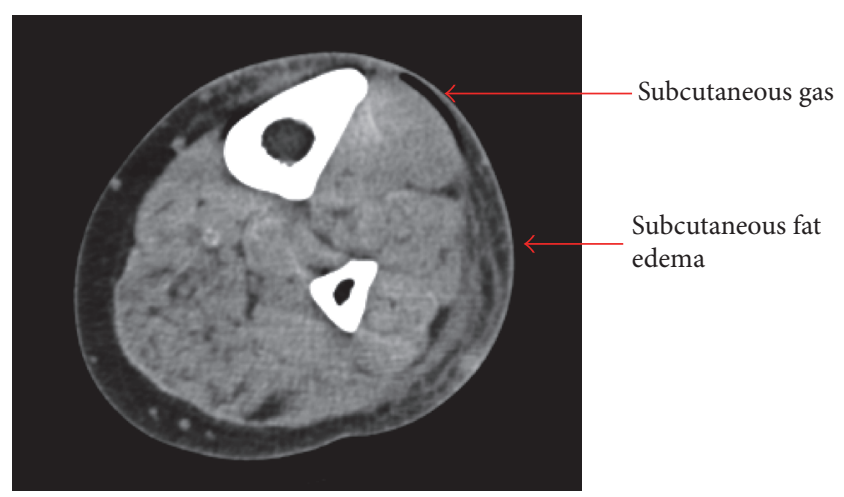

FIgURE 2: CT scan of the left lower extremity is displayed. Small amount of gas and subcutaneous fat edema present in anterior and lateral leg.

procedures along with an above-the-knee amputation. He stayed in the hospital for a total of three weeks prior to discharge to a rehabilitation facility.

\section{Discussion}

We describe the case of a patient who developed Clostridium septicemia manifesting as NF requiring amputation. Our patient was elderly (69 years old) with CLL complicated by hypogammaglobulinemia, which may itself have predisposed him to NF [18]; however the temporal relationship to rituximab therapy suggests that the treatment may have increased his susceptibility [19]. In the eight other patients we identified in the literature, all developed NF within 2 months of their last rituximab treatment (Table 1) which is congruent with prior descriptions of a temporal relationship between rituximab and severe infections in rheumatologic disease registries $[19,20]$. However a systematic review and metaanalysis of the risk of infections in patients with lymphoma treated with rituximab did not demonstrate a relative increase in the incidence of severe infections when added to standard chemotherapy [21], and a similar study did not find increased risk of severe infections in RA patients [22].

Besides rituximab-induced necrotizing fasciitis, other drug-related necrotizing fasciitis cases in immunocompromised patients have been previously reported in the literature, including associations with systemic corticosteroids [23], tumor necrosis factor-alpha (TNF- $\alpha$ ) inhibitors [24], nonsteroidal anti-inflammatory drugs [25], and other immunosuppressants such as tocilizumab [26] and bortezomib [27]. Although it is unclear whether the primary precipitating factor for necrotizing fasciitis is from immunosuppressive pharmacologic therapy, preexisting immunodeficiency, or malignancy, the temporal occurrence of necrotizing fasciitis was noted to occur closer to administration of immunosuppressant therapy in most cases.

NF is classified into two groups: type 1, a polymicrobial infection from anaerobes including Clostridia, gram-negative rods, and gram-positive cocci, and type 2, a monomicrobial infection often due to Group A Streptococcus [2]. Risk factors 


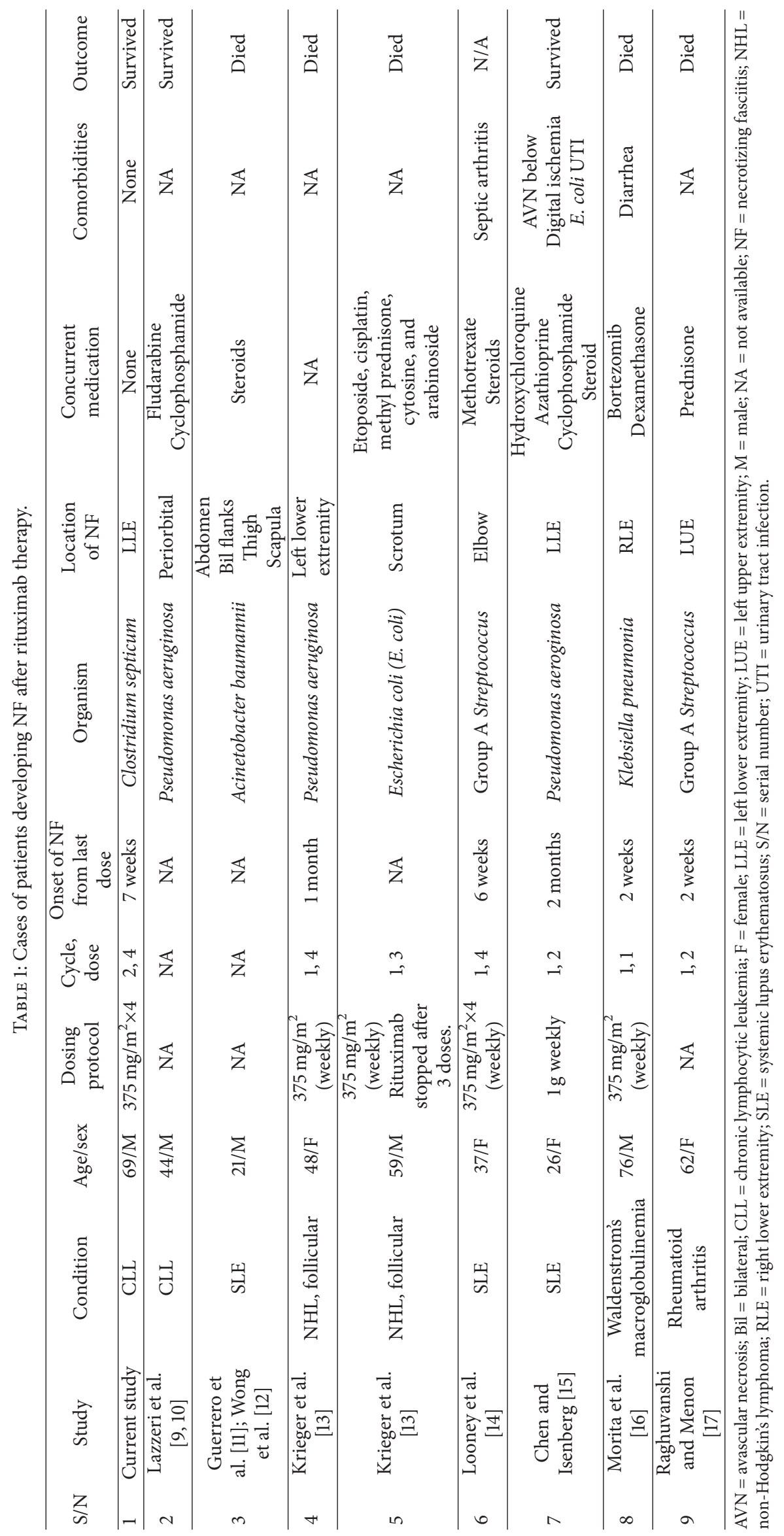


for NF infection include immunosuppression, diabetes mellitus, trauma, or recent surgery and intravenous drug use [18]. Interestingly, although polymicrobial type $1 \mathrm{NF}$ is commonly associated with immune impairment, our patient and all the cases we identified had monomicrobial NF. This suggests that the mechanism may have been initial bacteremia and seeding of that organism in otherwise viable tissue rather than overgrowth of polymicrobial bacteria in tissue with limited blood supply that typically characterizes type $1 \mathrm{NF}$.

Monomicrobial infection is usually associated with grampositive infections; however gram-negative monomicrobial NF is being increasingly reported [28]. Sixty-seven percent $(67 \%)$ of the cases we reviewed had gram-negative organisms implicated. Yahav et al. in a single-center study compared gram-negative and gram-positive monomicrobial NF and found that gram-negative monomicrobial NF was associated with mostly immunocompromised patients and higher mortality rates [29]. Our patient had a monomicrobial infection with Clostridium septicum, a gram-positive anaerobe. Clostridium septicum NF has been linked with underlying malignancy, particularly colon cancer and hematological malignancies [30]. In a recent review, $61 \%$ of adult patients with Clostridium septicum NF had gastrointestinal malignancies [30]. Notably, our patient had a normal colonoscopy two years prior to admission.

Of those reporting fatalities in our review, five of the eight patients $(63 \%)$ died. The death rate in this case series was in the higher range of what is reported in the literature, which may be attributable to the impaired immune response in patients receiving anti-B-cell therapies. Lee et al. found that patients with gram-negative NF presented with more severe sepsis [31].

\section{Conclusion}

Rituximab used in conjunction with steroids and other immunosuppressant agents may increase the risk of serious infections such as NF; other important factors which increase the risk of serious infections while on rituximab include elderly age and hypogammaglobulinemia. Emergent surgical consultation and fasciotomy should be performed, as delay in treatment has been associated with increased mortality. Further studies should investigate the relationship between rituximab and NF.

\section{Conflicts of Interest}

The authors declare that they have no conflicts of interest.

\section{References}

[1] K. S. Kotrappa, R. S. Bansal, and N. M. Amin, "Necrotizing fasciitis," American Family Physician, vol. 53, no. 5, pp. 16911696, 1996.

[2] T. W. Hakkarainen, N. M. Kopari, T. N. Pham, and H. L. Evans, "Necrotizing soft tissue infections: review and current concepts in treatment, systems of care, and outcomes," Current Problems in Surgery, vol. 51, no. 8, pp. 344-362, 2014.

[3] B. J. Childers, L. D. Potyondy, R. Nachreiner et al., "Necrotizing fasciitis: a fourteen-year retrospective study of 163 consecutive patients," The American Journal of Surgery, vol. 68, pp. 109-116, 2002.

[4] M. Y. Mok, S. Y. Wong, T. M. Chan, W. M. Tang, W. S. Wong, and C. S. Lau, "Necrotizing fasciitis in rheumatic diseases," Lupus, vol. 15, no. 6, pp. 380-383, 2006.

[5] C. Fang, W. Xu, and J.-Y. Li, "A systematic review and metaanalysis of rituximab-based immunochemotherapy for subtypes of diffuse large B cell lymphoma," Annals of Hematology, vol. 89, no. 11, pp. 1107-1113, 2010.

[6] G. Gao, X. Liang, J. Jiang et al., "A systematic review and metaanalysis of immunochemotherapy with rituximab for B-cell non-Hodgkin's lymphoma," Acta Oncologica, pp. 1-11.

[7] B. H. Rovin, R. Furie, K. Latinis et al., "Efficacy and safety of rituximab in patients with active proliferative lupus nephritis: the Lupus Nephritis Assessment with Rituximab Study.," Arthritis and rheumatism, vol. 64, no. 4, pp. 1215-1226, 2012.

[8] P. Emery, A. Deodhar, and W. F. Rigby, "Efficacy and safety of different doses and retreatment of rituximab: A randomised, placebo-controlled trial in patients who are biological naive with active rheumatoid arthritis and an inadequate response to methotrexate (Study Evaluating Rituximab's Efficacy in MTX iNadequate rEsponders (SERENE)) (Annals of the Rheumatic Diseases (2010) 69, (1629-1635))," Annals of the Rheumatic Diseases, vol. 70, no. 8, p. 1519, 2011.

[9] D. Lazzeri, T. Agostini, M. Figus, M. Nardi, M. Pantaloni, and S. Lazzeri, "More on periorbital infections following therapy with biological agents," Cutaneous and Ocular Toxicology, vol. 30, no. 4, pp. 338-339, 2011.

[10] D. Lazzeri, S. Lazzeri, M. Figus et al., "Periorbital necrotising fasciitis," British Journal of Ophthalmology, vol. 94, no. 12, pp. 1577-1585, 2010.

[11] D. M. Guerrero, F. Perez, N. G. Conger et al., "Acinetobacter baumannii-associated skin and soft tissue infections: recognizing a broadening spectrum of disease," Surgical Infections, vol. 11, no. 1, pp. 49-57, 2010.

[12] C. Wong, H. Chang, S. Pasupathy, L. Khin, J. Tan, and C. Low, "Necrotizing fasciitis," The Journal of Bone and Joint SurgeryAmerican Volume, vol. 85, no. 8, pp. 1454-1460, 2003.

[13] J. A. Krieger, J. M. Merin, and I. Rabinowitz, "Necrotizing fasciitis following rituximab therapy," Journal of Oncology Pharmacy Practice, vol. 8, no. 4, pp. 127-129, 2002.

[14] R. J. Looney, J. H. Anolik, D. Campbell et al., "B cell depletion as a novel treatment for systemic lupus erythematosus: a phase I/II dose-escalation trial of rituximab," Arthritis and Rheumatism, vol. 50, no. 8, pp. 2580-2589, 2004.

[15] Y. T. Chen and D. Isenberg, "Necrotizing fasciitis in systemic lupus erythematosus: a case report and literature review," in Lupus science \& medicine, vol. 1, p. 10, DOI, 10.1136/lupus-2014000008, 2014.

[16] T. Morita, T. Ugai, T. Tanimoto, and K. Matsue, "Necrotising fasciitis after bortezomib and dexamethasone-containing regimen in an elderly patient of Waldenström macroglobulinaemia," BMJ case reports, vol. 2014, 2014.

[17] S. Raghuvanshi and A. Menon, "A fulminant case of necrotising fasciitis secondary to rituximab in a patient with rheumatoid arthritis," Annals of the Rheumatic Diseases, vol. 71, no. Suppl 3, pp. 671.7-671, 2014.

[18] D. A. Anaya and E. P. Dellinger, "Necrotizing soft-tissue infection: diagnosis and management," Clinical Infectious Diseases, vol. 44, no. 5, pp. 705-710, 2007. 
[19] J.-E. Gottenberg, P. Ravaud, T. Bardin et al., "Risk factors for severe infections in patients with rheumatoid arthritis treated with rituximab in the autoimmunity and rituximab registry," Arthritis and Rheumatism, vol. 62, no. 9, pp. 2625-2632, 2010.

[20] B. Terrier, Z. Amoura, P. Ravaud et al., "Safety and efficacy of rituximab in systemic lupus erythematosus: results from 136 patients from the French autoimmunity and rituximab registry," Arthritis and Rheumatism, vol. 62, no. 8, pp. 2458-2466, 2010.

[21] S. Lanini, A. C. Molloy, P. E. Fine, A. G. Prentice, G. Ippolito, and C. C. Kibbler, "Risk of infection in patients with lymphoma receiving rituximab: Systematic review and meta-analysis," BMC Medicine, vol. 9, article no. 36, 2011.

[22] C. Salliot, M. Dougados, and L. Gossec, "Risk of serious infections during rituximab, abatacept and anakinra treatments for rheumatoid arthritis: Meta-analyses of randomised placebocontrolled trials," Annals of the Rheumatic Diseases, vol. 68, no. 1, pp. 25-32, 2009.

[23] Ö. Ekiz, B. B. Şen, E. N. Rifaioğlu, T. Özgür, M. U. Inan, and Ç. A. Doğramaci, "Necrotizing fasciitis in a patient with bullous pemphigoid treating with systemic steroid," Cutaneous and Ocular Toxicology, vol. 32, no. 3, pp. 252-254, 2013.

[24] A. T. Y. Chan, V. Cleeve, and T. J. Daymond, "Necrotising fasciitis in a patient receiving infliximab for rheumatoid arthritis," Postgraduate Medical Journal, vol. 78, no. 915, pp. 47-48, 2002.

[25] C. Souyri, "Severe necrotizing soft-tissue infections and nonsteroidal anti-inflammatory drugs," Clinical and Experimental Dermatology, vol. 33, no. 3, pp. 249-55, 2008.

[26] N. Hashimoto, T. Yamaoka, H. Koguchi-Yoshioka et al., "Development of necrotising fasciitis in a patient treated for rheumatoid arthritis with tocilizumab," Acta Dermato-Venereologica, vol. 95, no. 3, pp. 370-371, 2015.

[27] A. Rosser, G. Swallow, R. A. Swann, and C. Chapman, "Salmonella enteritidis necrotising fasciitis in a multiple myeloma patient receiving bortezomib," International Journal of Hematology, vol. 91, no. 1, pp. 149-151, 2010.

[28] N.-C. Cheng, Y.-C. Yu, H.-C. Tai et al., "Recent trend of necrotizing fasciitis in taiwan: Focus on monomicrobial Klebsiella pneumoniae necrotizing fasciitis," Clinical Infectious Diseases, vol. 55, no. 7, pp. 930-939, 2012.

[29] D. Yahav, H. Duskin-Bitan, N. Eliakim-Raz et al., "Monomicrobial necrotizing fasciitis in a single center: The emergence of Gram-negative bacteria as a common pathogen," International Journal of Infectious Diseases, vol. 28, pp. 13-16, 2014.

[30] I. Srivastava et al., "Spontaneous C. septicum gas gangrene: a literature review," Anaerobe, 2017.

[31] C.-Y. Lee, L.-T. Kuo, K.-T. Peng, W.-H. Hsu, T.-W. Huang, and Y.-C. Chou, "Prognostic factors and monomicrobial necrotizing fasciitis: gram-positive versus gram-negative pathogens," $B M C$ Infectious Diseases, vol. 11, article 5, 2011. 


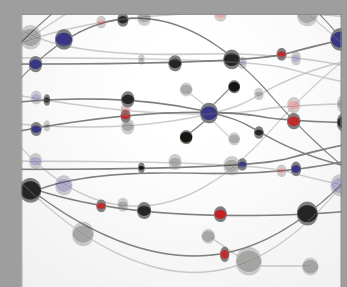

The Scientific World Journal
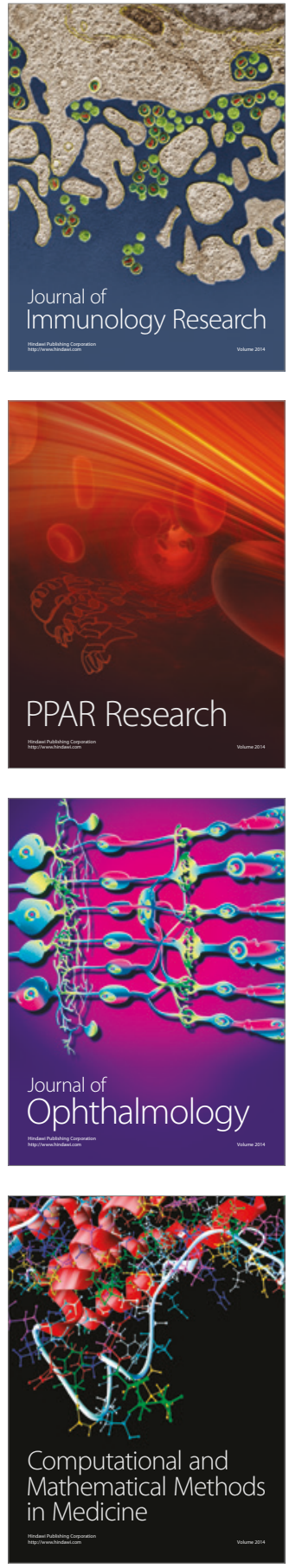

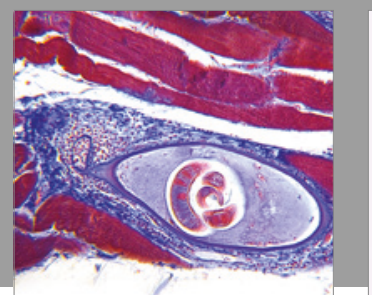

Gastroenterology Research and Practice
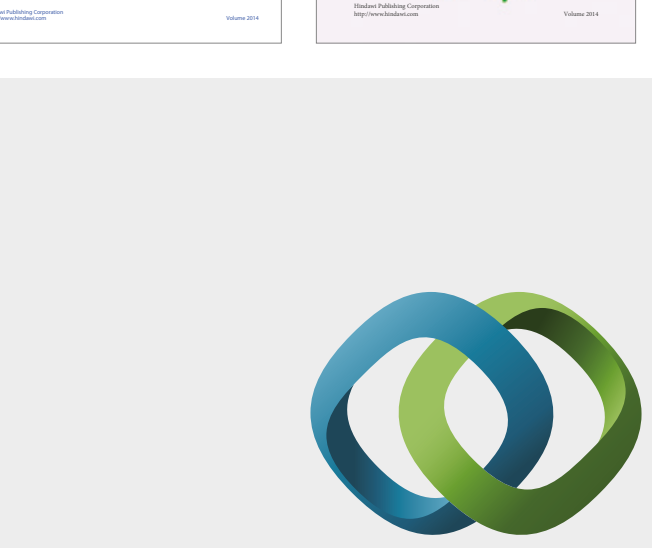

\section{Hindawi}

Submit your manuscripts at

https://www.hindawi.com
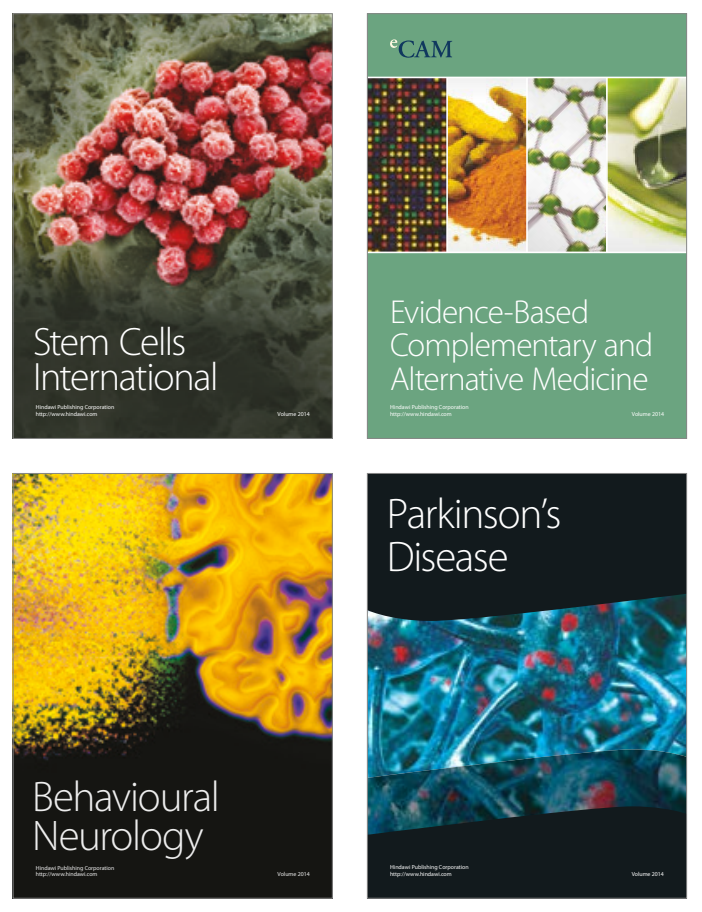
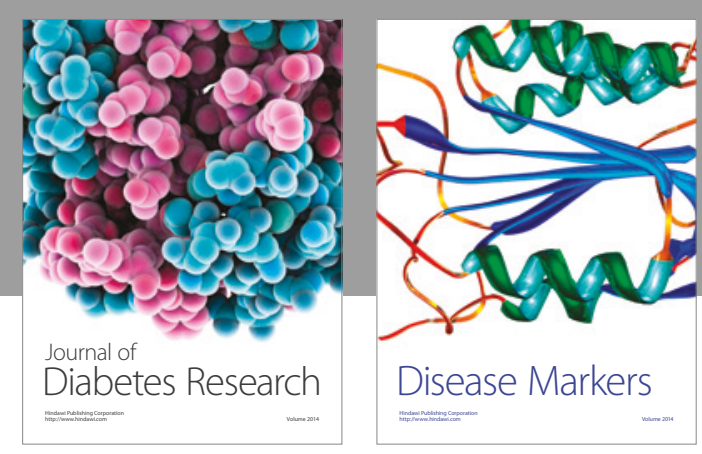

Disease Markers
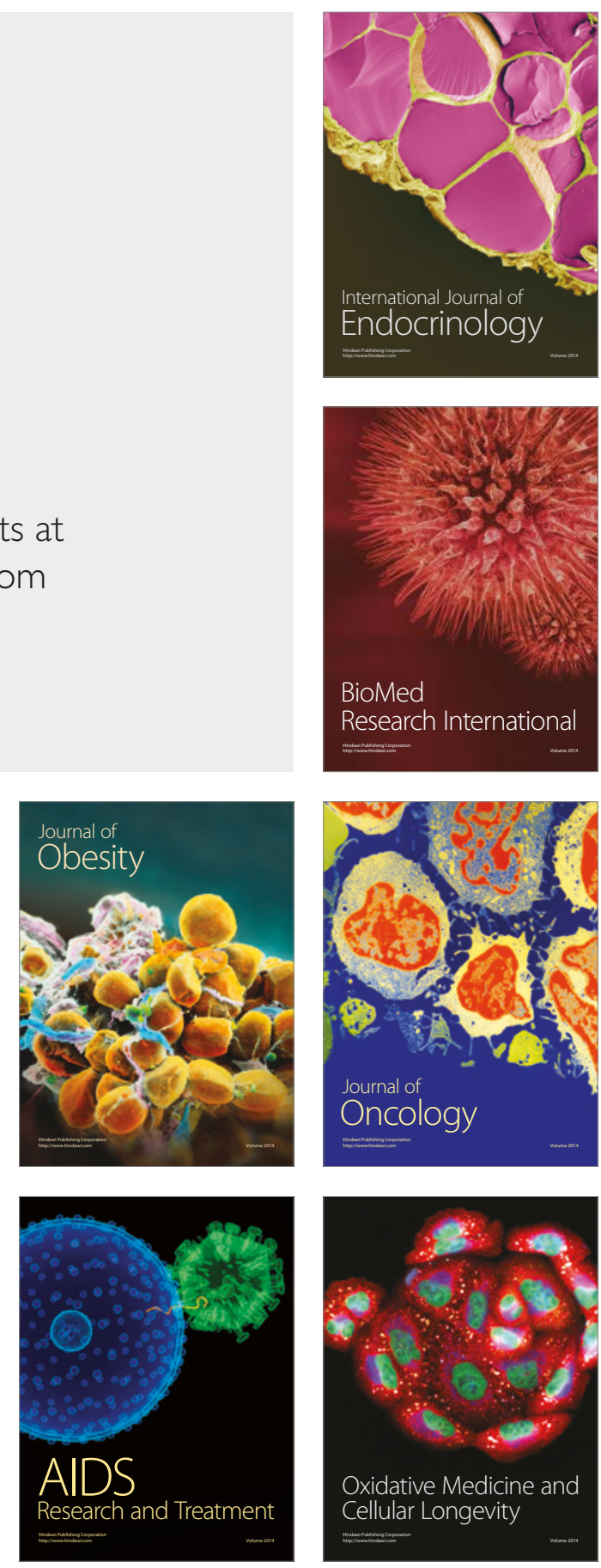